Research Article

\title{
Liquid Crystal Display (LCD) and Organic Light Emitting Diode (OLED) Applications on Natural Fibre Reinforced Polymer Matrix Composites
}

\author{
V. Senthil Nayagam (iD, ${ }^{1}$ Anamika, ${ }^{2}$ D. Gopinath, ${ }^{3}$ K. Vetri Velmurugan, ${ }^{4}$ Rani Fathima, \\ Mary Joy Kinol, ${ }^{6}$ Prasath Alias Surendhar, ${ }^{7}$ and David Christopher $\mathbb{D}^{8}$ \\ ${ }^{1}$ Department of Electrical and Electronics Engineering, Sathyabama Institute Science and Technology, Chennai 600119, \\ Tamil Nadu, India \\ ${ }^{2}$ Department of Electrical and Electronics Engineering, Galgotias College of Engineering and Technology, \\ Greater Noida 201310, India \\ ${ }^{3}$ Department of Mechatronics Engineering, SRM Institute of Science and Technology, Chennai 603203, Tamil Nadu, India \\ ${ }^{4}$ Department of Mechanical Engineering, Sri Sairam Engineering College, Chennai 600044, Tamilnadu, India \\ ${ }^{5}$ Department of Engineering, Electrical Section, University of Technology and Applied Sciences, Al Musanna, Oman \\ ${ }^{6}$ Department of Electronics and Communication Engineering, Saveetha School of Engineering, SIMTAS, Saveetha University, \\ Chennai, Tamil Nadu, India \\ ${ }^{7}$ Department of Biomedical Engineering, Bharath Institute of Higher Education and Research, Chennai 600073, \\ Tamilnadu, India \\ ${ }^{8}$ Department of Mechanical Engineering, College of Engineering, Wolaita Sodo University, Wolaita Sodo, Ethiopia
}

Correspondence should be addressed to David Christopher; david.santosh@wsu.edu.et

Received 8 September 2021; Accepted 28 October 2021; Published 26 November 2021

Academic Editor: P. Ganeshan

Copyright $(2021$ V. Senthil Nayagam et al. This is an open access article distributed under the Creative Commons Attribution License, which permits unrestricted use, distribution, and reproduction in any medium, provided the original work is properly cited.

\begin{abstract}
Natural materials are the alternative source for the manufacture of products due to environmental requirements. Hot injection moulding techniques make the composite product with fibreglass, granite waste filler, and polylactic acid (PLA). Five samples of each set and sampled with better hardness varied the volumetric percentage of glass fibre and the waste nanogranite particles. This effort is mainly concerned with evaluating the wear of dry sliding and friction of composites. Varying 15, 25, 35, and 45 N load, 750 and $1500 \mathrm{~m}$ sliding distance tested the composite materials, respectively. Parametric condition experiments were carried out at the stated process to record answers. Nanogranite composite materials are better than higher concentrations of glass fibre in PLA matrices composites, which are more resistant to wear and friction coefficients. The nanogranite powder is added with the filler element in the PLA matrix to provide a better coefficient of wear and rubbing. A high load of $45 \mathrm{~N}$ and a sliding distance of $1500 \mathrm{~m}$ were measured at low wear and low friction coefficients.
\end{abstract}

\section{Introduction}

Composite materials offer better performance, high specified strength and rigidity, excellent fatigue resistance, low weight, and low design flexibility than conventional structural materials. The winning alliance has become these properties, which leads to new space for fibrous composites. Reinforced plastic fibres and epoxy composites are used widely in automotive and aerospace industries, in addition to other orthodox engineering materials, given their enhanced properties. Researchers have extensively studied the incomparable performance of polymer matrix composite (PMC) materials. The compounds filled have scratch-resistance and can be found in automotive segments for piston blocks, cylinders, callipers, cylinder embedding rings, microwave channels, pulses, spatial structures, and vibrators 
segment [1-7]. However, there is much information about composites of glass fibre epoxy [8]. The Glass fibre composite (GFC) exhibits increased resistance to indentation. The GFC exhibits increased resistance to indentation, and also, GFC has also widely employed several applications such as car bodies and brake sections, aircraft rates, and brake segments [9]. The GFC has increased resistance to indentation. Glass fibre reinforced plastics have a preferred density and excellent mechanical and thermal properties and also widely used in automobile and aerospace sectors [10]. E-glass fibre is of great importance between different glass fibres and study for its exceptional characteristics. E-glass is thermally resistant and resistant to corrosion and has good strength. In the electrical isolation industries and structural sectors, e-glass found helpful in cars [11].

Generally, PMCs are extensively utilized in aviation, automotive, and electronic applications. An electronic visual display serves as a video display for displaying images sent over the Internet. Televisions, computer monitors, cell phones, and other electronic visual displays are examples. Light-emitting diodes (LEDs) and liquid crystal displays (LCDs) are the two most common display systems. When triggered by applying an appropriate voltage, an LED is a two-lead semiconductor light source that generates light due to the electroluminescent effect. The energy bandgap of the semiconductor determines the hue of light. A liquid crystal display (LCD) makes use of features, including light modulation. LCDs have several advantages over LEDs, including lower power usage. Figure 1 reveals the structure of a typical LCD. A light-emitting diode (LED) with an organic emissive electroluminescent layer that produces light when an electric current is applied is known as an organic light-emitting diode (OLED). An organic materials layer is sandwiched between two electrodes in a conventional OLED (anode and cathode). All of the components are placed on a transparent electrically conductive substrate like ITO. Because of their outstanding performance, versatility, and ease of production, OLEDs have obtained a lot of interest as next-generation lighting and displays in recent years. Figure 2 reveals the typical construction of an OLED.

The sliding wear of fibre-reinforced composites is affected by the material durability [12]. The compound's load, sliding speed, and distance affect the friction and wear- excessive wear found in more excellent bags during the glass fibre epoxy composites wear test $[13,14]$. The sliding wear distance limit significantly affects composite wear [15]. Studies examined for different fillers on cryogenic exposure and glass fibre epoxy composite [16]. The compression moulding technique helped develop polylactic acid matrix (PLA) composites reinforced with chitosan microparticles. The findings show that the mechanical and wear characteristic of the PLA matrix composites is improved positively. PLA has been used to develop food packaging, textiles, and, more recently, engineering polymers. Optimal chitosan reinforcement values for mechanical properties and wear resistance observed 6 wt. percent [17]. The most suitable biodegradable polymer is polylactic acid for wear study. Recent days have seen increased demand for the replacement of petroleum-based polymers [18]. Injection moulding goals include high productivity, design flexibility, low labor costs, and a low scrap rate. Figure 3 reveals the application of different manufacturing techniques in fabrication of structural components.

Since polymer materials are easy to fabricate, lightweight, cheap, and easy to make, they can manufacture a minor machine component. Also, a significant challenge for the existing situation is finding substitute materials with an equal force to the petroleum-based polymer. As PLA has enough mechanical properties as a renewable source polymer, it is used widely, such as packing, rolling, and biomedical applications. PLA's nature is very fragile and has low thermal conductivity, and therefore it is also essential to increase the strength of this polymer. Because of this, the use of PLA for machine components is more suitable in low load and low-speed applications $[19,20]$.

It is harder to analyse the usury thoroughly and frictional characteristics mixed with different materials and their synergism in the friction structure [21]: barium sulphate, caroline, and rubber filler like barium sulphate and cashew nut used. The filler component is used for design, cost reduction, and increase in manufacturability [22]. In brake pads with higher content, the filler used as Lignin decreased the execution of brake pads marginally. For brake pads, $10 \%$ lignin composite is chosen as the most suitable material because the general properties of the commercially available brake pads closely coordinated in its execution [23]. The excess assessment clearly shows that natural fibres in alternative materials are essential for formulating frictional materials with ideal binders and fillers. They consider that it is necessary to use natural binders and fillers connected with the supply and characterization of frozen material. Surprisingly, little research is conducted on composite fusions' tribological properties and available natural fibres [24]. Numerous studies on the tribological performance of composite reinforced fibre have reported before. Constant sliding distances of 300 metres and temperature $300^{\circ} \mathrm{C}$ are examined in applied loads $(5 \mathrm{~N}, 10 \mathrm{~N}, 14 \mathrm{~N}$, and $37 \mathrm{~N})$ for mechanical and abrasive Nylon 6 and GFR Nylon 6 wearing at a varying content glass fibre $(0-30 \mathrm{wt} \%)$. The findings have demonstrated the lowest specified wear rate of $30 \%$ of glass fibre content in Nylon $6[25,26]$. The glass fibres in PEEK and PEEK composite were examined in 30 wt. per cent, and GF/PEEK found to be excellent in wear resistance than PEEK. The authors in [27] studied tribology performance of PEEE under dry and water-lubricated conditions of pure polyether ether ketone (PEEK) and $30 \mathrm{wt}$. percent fibreglass (GFR). The results indicated that when the pressure increased, a specific wear rate and the frictional coefficient for both composites increase slightly. The values of particular wear rates and rib coefficients were also less than the dry sliding condition in the water-lubricated condition. The GFR strengthened PEEK $30 \mathrm{wt}$. percent demonstrated strong wear resistance compared with pure PEEK [27]. The tribology of the glass epoxy composite composites with $\mathrm{SiC}$ and secondary filler in graphite particles was examined. $\mathrm{SiC}$ and graphite were 


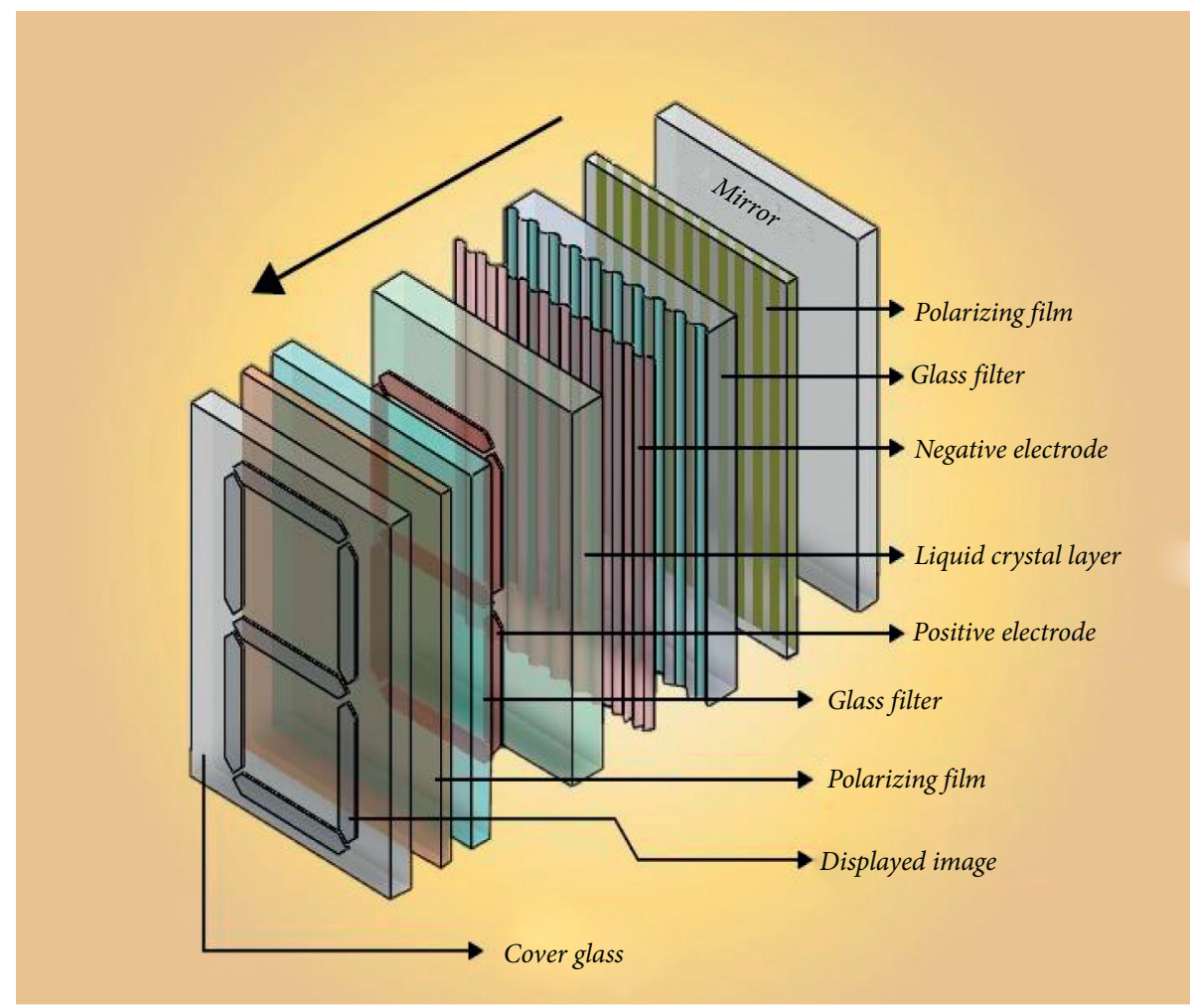

Figure 1: Structure of a typical LCD.

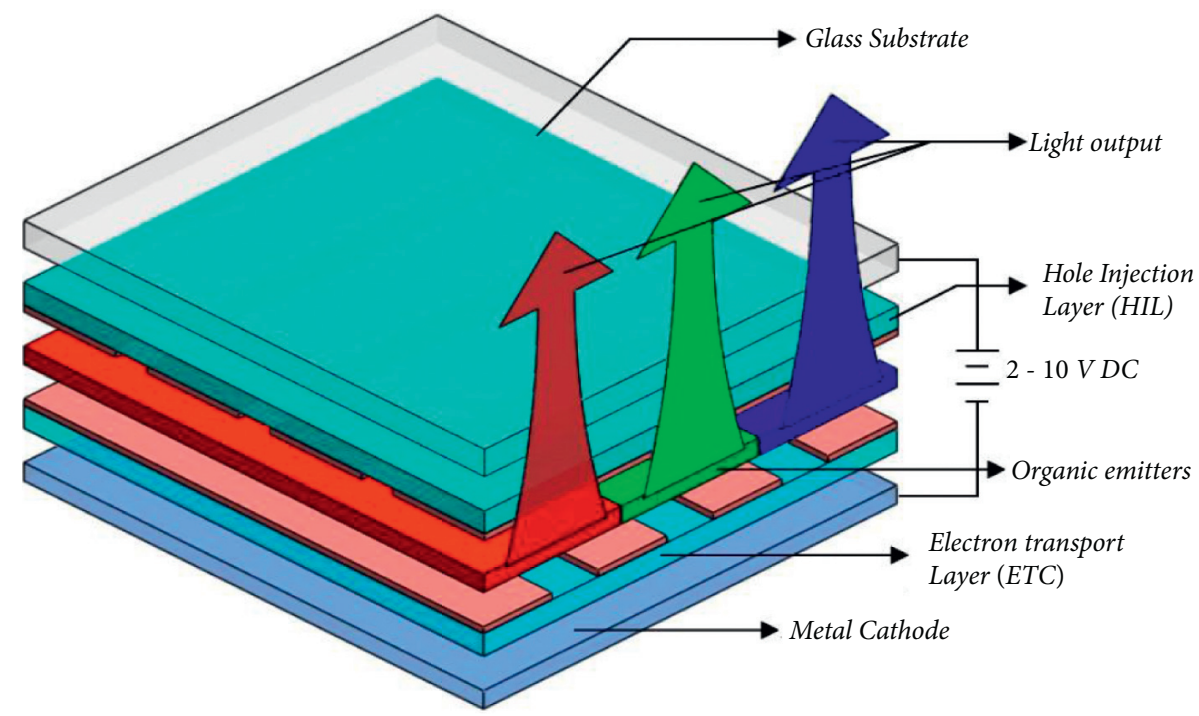

Figure 2: Typical construction of an OLED.

significantly improved in wear resistance properties as filler materials in glass/epoxy composites. In [28], three short E-glass fibre reinforced polyester abrasive wear behaviours were studied with and without filler material. They found that composite wear behaviour depends on different test parameters, including abrasive particle size, sliding speed, loading, and so on. It also observed that a higher fraction of the weight of polyester composites improves wear resistance. The current work focused on producing and investigating the tribological properties, of the different weight percentages of reinforced glass fibre, and PLA matrix with varying weight of waste granite powder. The overview of this experimental work is illustrated in Figure 4.

\section{Experimental Plans}

Polylactic acid is the most modified kind of phenol (PLA). It has the necessary phenolic characteristics that work as a suitable binder with high resistance to wear and tear. 


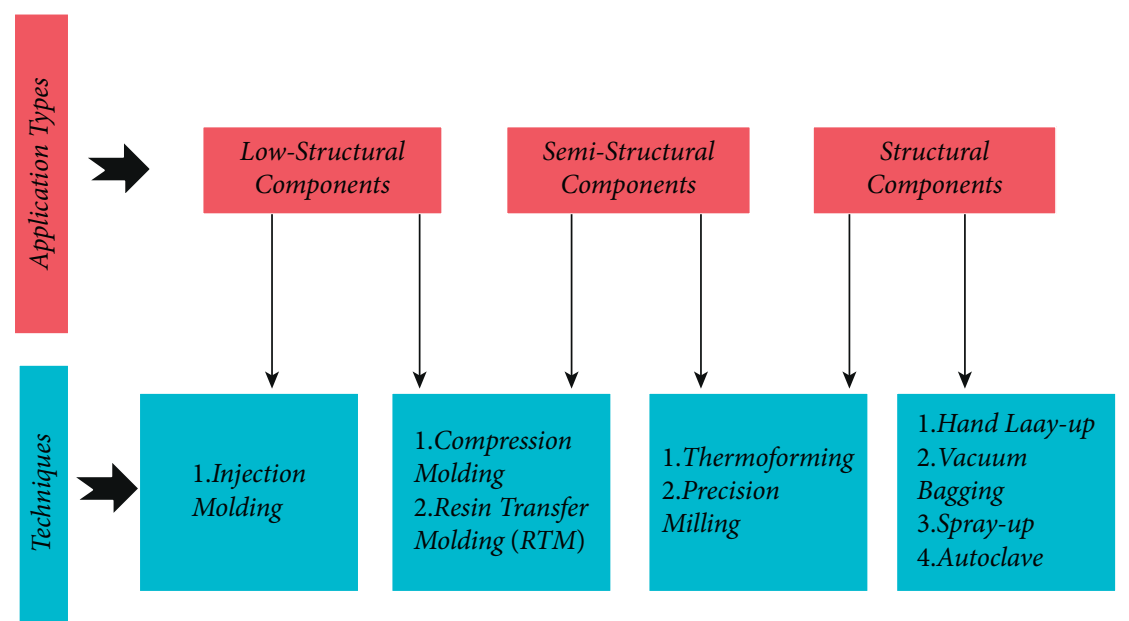

Figure 3: Application of different manufacturing techniques in fabrication of structural components.

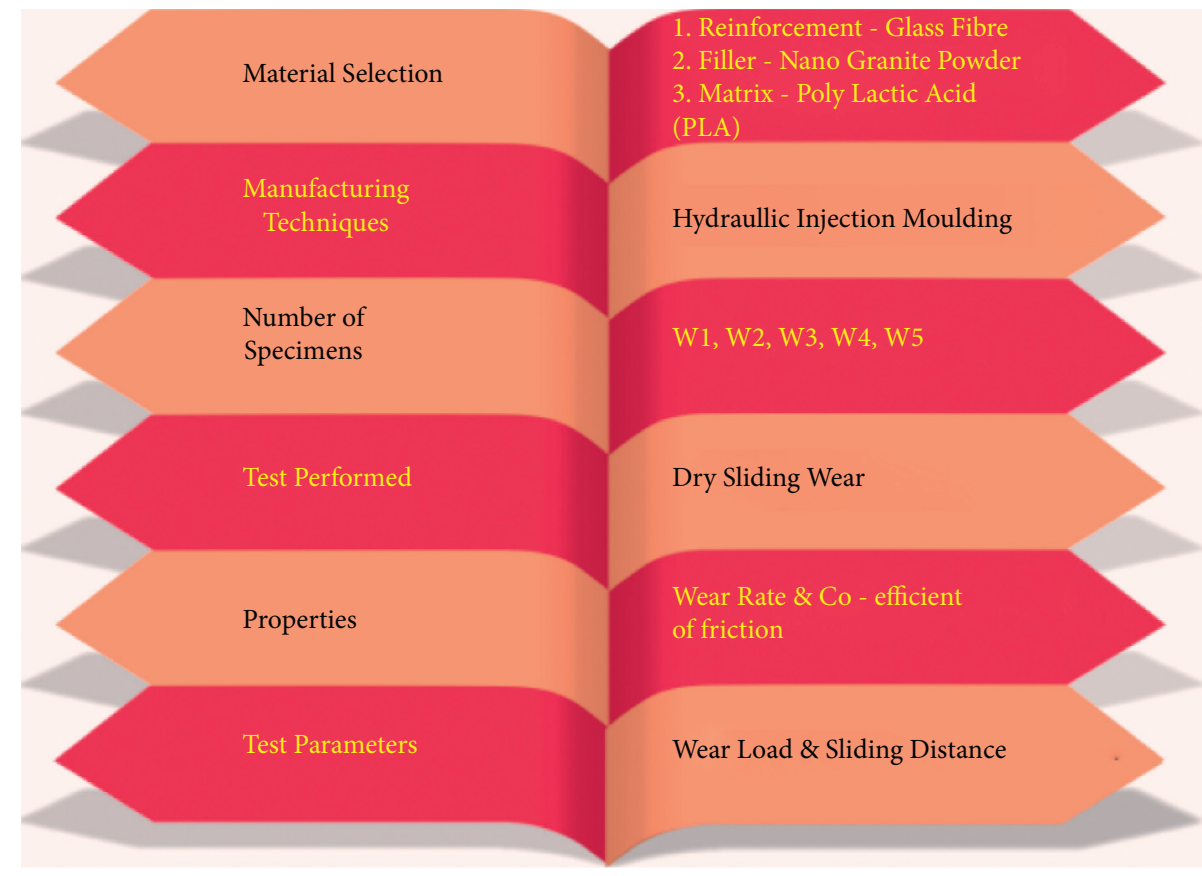

FIgURE 4: Overview of this experimental work.

Flexibility, thermal stability, and impact resistance decrease the friction coefficient. In particular, for brake fitting, the thermosetting and binding properties are also combined. Freezes and increased fading strength, impact resistance, flexibility, rapid thermal disappearance, good noise resistance, wear resistance, improved reliability, heat resistance, and hygroscopic resistance have also reported. It is applicable in the polymers industry due to its polymerization versatility and low-cost modification of chemical products. The addition of nanogranite particles provides a better binding of glass fibre. PLA can be made the preferred initial adhesive by using its high extremity and innate PLA touchiness, and the ease with liquid is made solid. The added value of nanogranite particulate fillers in the samples improves wear and shear resistance in the counter-face zone to reduce the removal of the material.
TABLE 1: The different chemical compositions of glass fibre in wt. \% (30).

\begin{tabular}{lccccccc}
\hline $\mathrm{SiO}_{2}$ & $\mathrm{Al}_{2} \mathrm{O}_{3}$ & $\mathrm{TiO}_{2}$ & $\mathrm{~B}_{2} \mathrm{O}_{3}$ & $\mathrm{CaO}$ & $\mathrm{MgO}$ & $\mathrm{Na}_{2} \mathrm{O}$ & $\mathrm{K}_{2} \mathrm{O}$ \\
\hline 55 & 14.00 & 0.2 & 7 & 022 & 01 & 0.5 & 0.3 \\
\hline
\end{tabular}

Table 1 reveals the various chemical compositions of glass fibre. For this study, the main components of the study were the use of glass fibres with liquid PLA and nanogranite particles for the five combinations of samples with varying proportions. The PLA matrix added an adequate volume of $4,6,8,10$, and $12 \%$ nano granite, along with $4,5,6,7$, and $8 \%$ glass fibre. Glass fibres are shown in Table 2 for physical and mechanical properties. Figure 5 reveals the graphical representation of twin screw extrusion process for making hybrid composite pieces. 
TABle 2: Physical and mechanical properties of glass fibre (30).

\begin{tabular}{lcccccc}
\hline $\begin{array}{l}\text { Density } \\
\left(\mathrm{g} / \mathrm{cm}^{3}\right)\end{array}$ & $\begin{array}{c}\text { Tensile strength } \\
(\mathrm{GPa})\end{array}$ & $\begin{array}{c}\text { Young's modulus } \\
(\mathrm{GPa})\end{array}$ & $\begin{array}{c}\text { Elongation } \\
(\%)\end{array}$ & $\begin{array}{c}\text { Coefficient of thermal } \\
\text { expansion }\end{array}$ & $\begin{array}{c}\text { Poison's } \\
\text { ratio }\end{array}$ & $\begin{array}{c}\text { Refractive index } \\
2.58\end{array}$ \\
\hline 3.445 & 72.3 & 4.8 & 54 & 0.2 & 1.558 \\
\hline
\end{tabular}

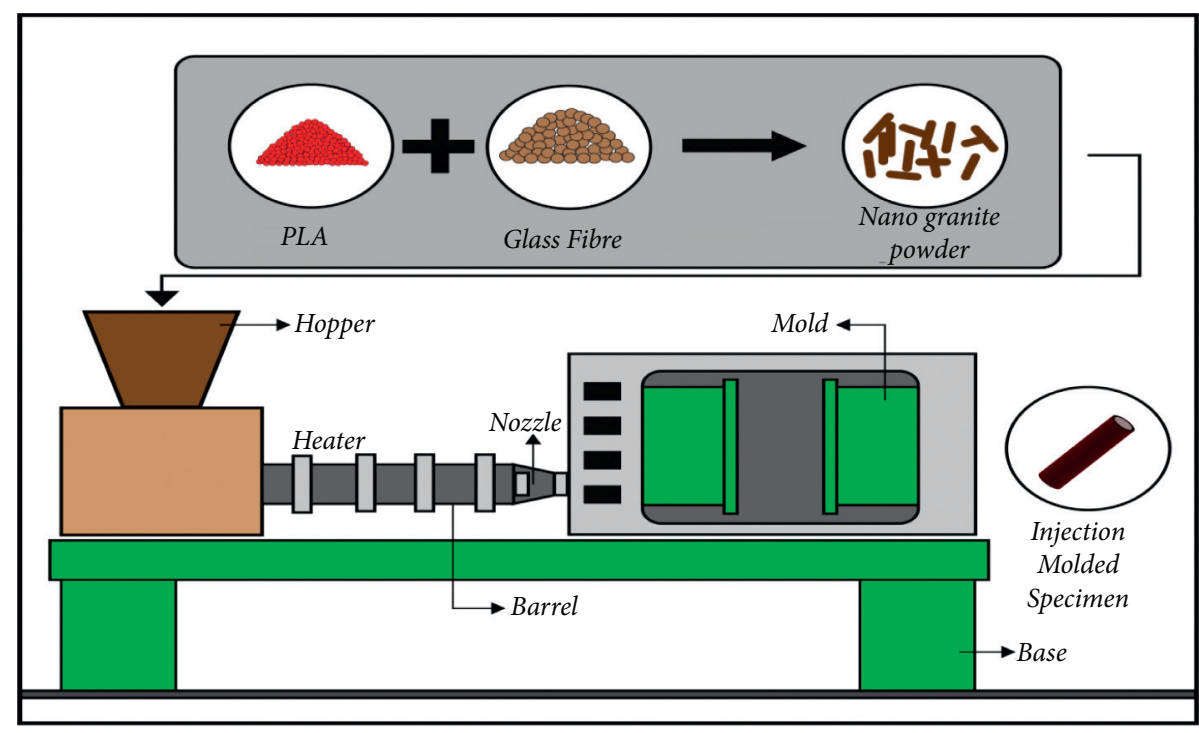

FIgURE 5: Twin screw extrusion process for making hybrid composite pieces.

The mixing is performed using a $500 \mathrm{rpm}$ mechanical stirrer to make a compound uniform mix to avoid the accrual. Before pouring, it was possible to use a thin wax layer on the inner surface of the form for release and removal of the samples with too minor damage. The preheated mould cavity transferred from the prepared homogeneous mix to the preheated metal moulds of $13 \mathrm{~mm}$ diameter and $45 \mathrm{~mm}$ length. The bolted mould has been stored for approximately 4 hours in a hydraulic press at $130^{\circ} \mathrm{C}$, guaranteeing complete consolidation and postcuring at $90^{\circ} \mathrm{C}$ in a heat air furnace.

Finally, for cylindrical expulsion, the compressive load of the prepared sample of size $13 \mathrm{~mm} \times 45 \mathrm{~mm}$ has been released. For all four samples of PLA, different tribological tests have prepared in the next step of our proposed work according to our planned, designed matrix. The compositions of each prepared sample are shown in Table 3.

The composites of $12 \mathrm{~mm}$ and $45 \mathrm{~mm}$ diameter are processed and tested with a pin on the tribometer under dry sliding conditions. A PLA (W1, W2, W3, W4, and W5) performed a composite test. In describing the material for the braking system, this wear testing method is commercially used in different conditions (dry and wet), and all tests were conducted at room temperature.

The specimen keeps in contact with the holder of the model with the $62 \mathrm{HRC}$ steel disc. The surface roughness of the sample and the steel disc is $0.9 \mu \mathrm{m}$ and $1.6 \mu \mathrm{m}$, respectively. Different process parameters are used to test the tribometer, such as load $15,25,35$, and $45 \mathrm{~N}$, slope range $750 \mathrm{~m}, 1500 \mathrm{~m}$, sliding runtime $(15 \mathrm{~min})$, and the track diameter $150 \mathrm{~mm}$. The process parameters also adjusted accordingly. A suitable frozen surface layer has established before each test performed at a preliminary stage of $130 \mathrm{kPa}$.
Each case before and after the trial examined the parallelism between the pin and the rotary disc. Before the test, acetone cleaned up the counter-face; $\mathrm{SiC}$ abrasive paper is used to polish the sample, and counter-face was correctly contacted. Figure 6 reveals the schematic diagram of pin on disc apparatus.

The nominal pin disc contact pressure was $13,27,42$, and $53 \mathrm{KPa}$, and these steps are used in earlier studies. A $0.1 \mathrm{mg}$ highly accurate digital weight indicator is used to calculate friction wear rate by measuring weight loss. The usage data are an average of four repeated tests in each particular sample. The researchers have used the same method of testing under appropriate standards. For all examples, tribological behaviours, like wear rate and friction coefficient, are taken, and values for further analysis are noted.

\section{Results and Discussion}

3.1. Wear Rate. Figures 7 and 8 interpret the sliding wear rate data of $\mathrm{W} 1, \mathrm{~W} 2, \mathrm{~W} 3, \mathrm{~W} 4$, and $\mathrm{W} 5$ composites at a sliding distance of $750 \mathrm{~m}$. The results of Figures 7 and 8 show that the nanogranite powder and glass fibre, which is PLA, are used as filler and reinforcements, and perform better against wear at different load conditions. The additional PLA and higher nanogranite powder reflect comparably less wear resistance to all stress conditions $(15 \mathrm{~N}, 250 \mathrm{~N}, 35 \mathrm{~N}$, and $45 \mathrm{~N})$

PLA is the most altered phenolic type. It includes essential elements that are straight phenolic and act as good wear resistance and an excellent tight binder. The addition of waste nanogranite powder is a better binding factor for glass fibres. PLA can be made the preferred initial adhesive using its high 
TABLE 3: Compositions of each prepared sample.

\begin{tabular}{lccc}
\hline Test specimen description & PLA (wt. \%) & Glass fibre (wt. \%) & Nanogranite powder (wt. \%) \\
\hline W1 & 93 & 3 & 4 \\
W2 & 89 & 6 & 5 \\
W3 & 85 & 9 & 6 \\
W4 & 81 & 12 & 7 \\
W5 & 77 & 15 & 8 \\
\hline
\end{tabular}

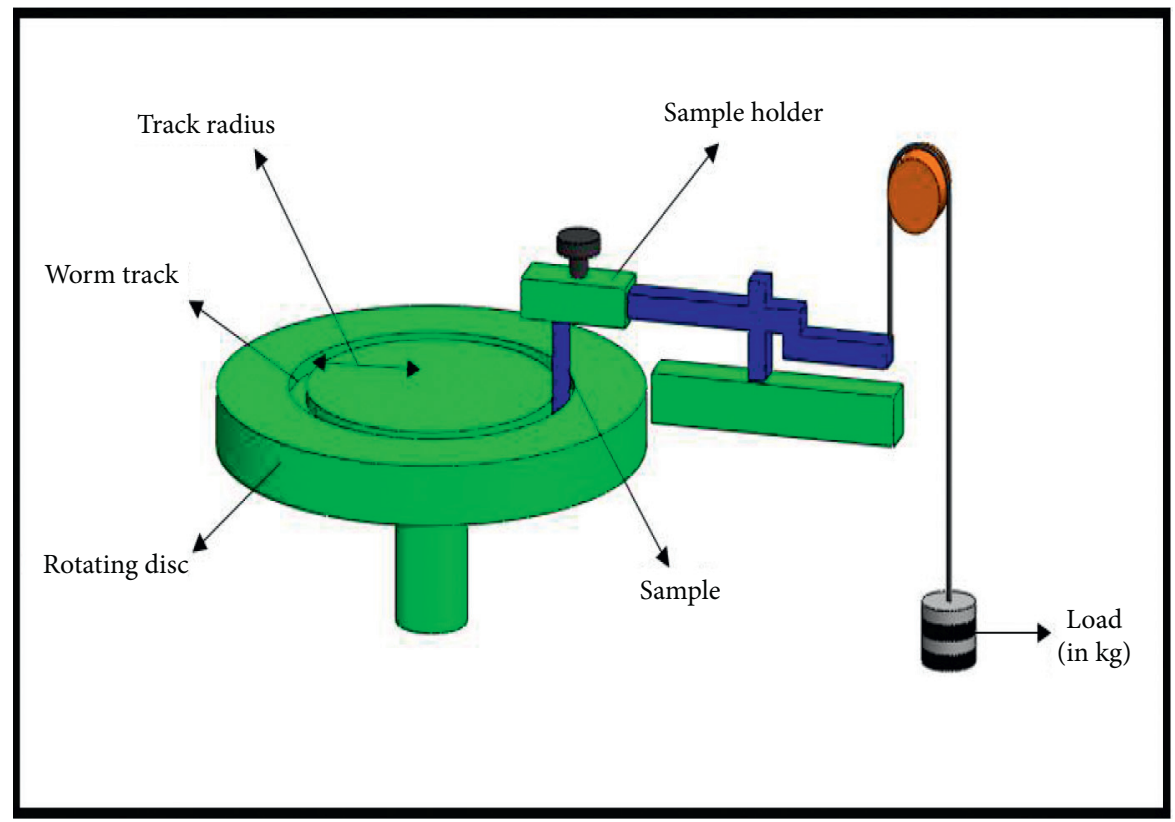

Figure 6: Schematic diagram of pin on disc apparatus.

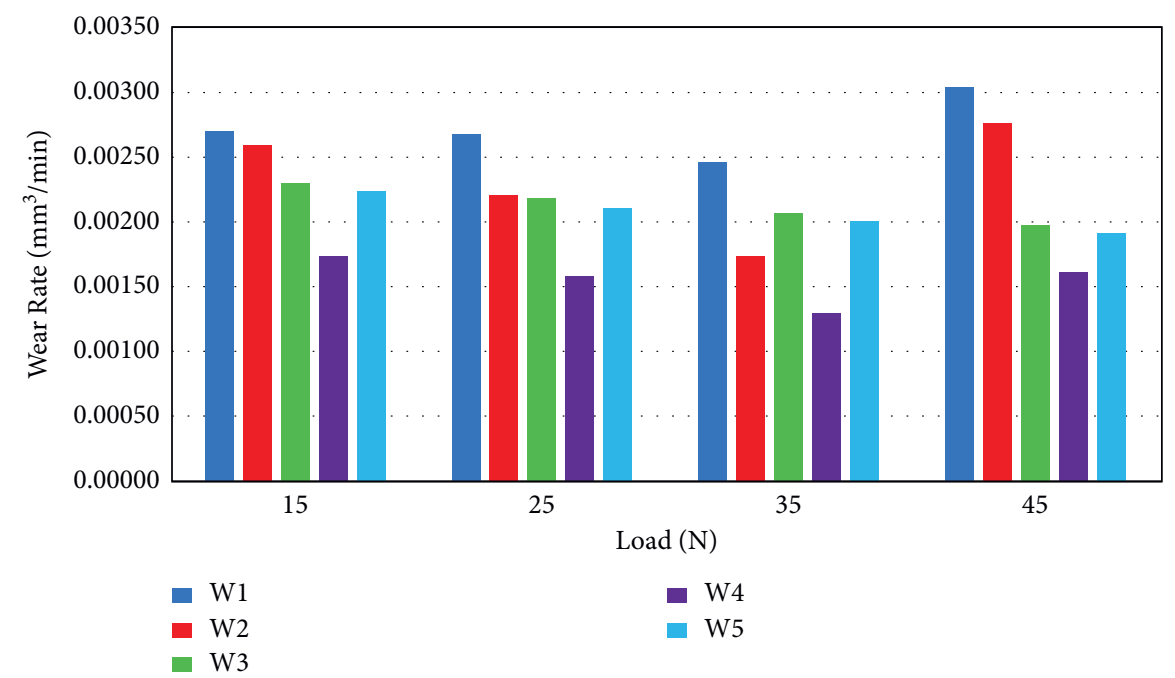

FIgURE 7: Variation on the wear rate of composites for $750 \mathrm{~m}$ sliding distance.

extremity and innate PLA touchiness and the ease with which liquid is made solid. The added value of the nanogranite powder filler waste in samples increases the wear strength and reduces the shear resistance in the rubbing zone against which the material evacuated. The unique wear behaviour of different charging composites is other matrix interfaces. Low load conditions reduce the pressure to cause the light waste material to be evacuated, which increases heavy explosions under high load conditions due to the rubbing effects of the disc and the composite material. The wear rate was higher at a low rotating distance, but the slide improved and became wearable, according to Figures 4 and 5 . 


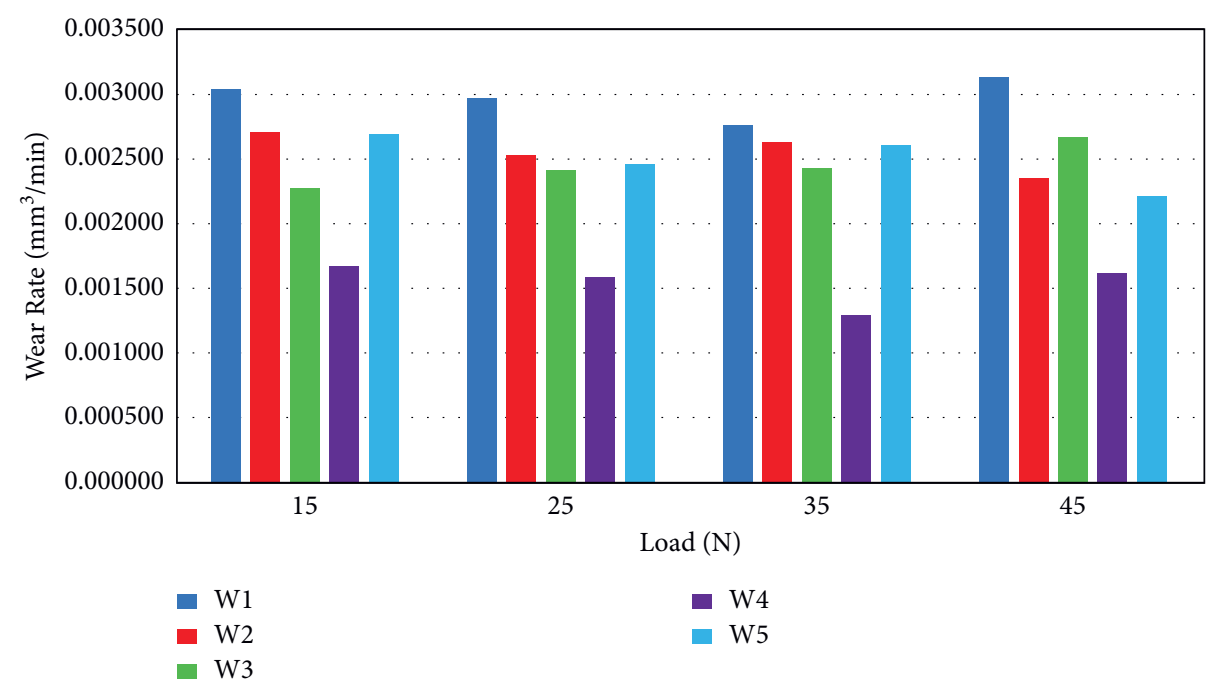

FIGURE 8: Variation on the wear rate of composites for $1500 \mathrm{~m}$ sliding distance.

Due to the application of stress, sliding length, and fillers exposed to opposition to wear, the pattern of wear rate in the specimen reduced in Figures 7 and 8. Initially, during exams, a large area was exhausted. The wear rate was higher. Later, wear debris dropped from the interface into the array, and plastic deformation formed the defensive layer over the fibre. The fillers and the PLA matrix area surface are also flushed, which led to a refusal of wear. The wear rate for W1 composites is high compared withPLA W4 composites, as shown in Figures 9 and 10 for sliding distances of $750 \mathrm{~m}$ and $1500 \mathrm{~m}$. That is why the zero content of the waste granite powder fillet which usually less interfacially links filler-PLA matrix areas.

In the investigations, the surface area of the PLA matrix was in more significant contact with the rotary counter-face. Due to the low surface hardness, the material evacuation took place more in the PLA matrix area than the filler and PLA matrix. In turn, composite PLA W4 compared with other PLA samples tends to show a lower wear rate, which could occur because the actual contact area of the PLA matrix and the filling content of the frictional composition increased. In wear expulsion, the comprehensive filler content had a vital role to play. Wear out was gradually reduced by increasing the filling content and surface hardness and reducing the thermal and mechanical load. The required amount of fillers in the composition enhanced through homogeneously blending the stuffing with the PLA matrix with the help of an automatic mixer. The PLA sample W4 shows less wear resistance because the PLA matrix interaction range is higher, and the composites do not fill. Compared with all other samples, the PLA sample W4 shows a lesser wear rate. The high polarity and inherent tackiness of PLA and their wear on the PLA matrix and the containing fillers may be the reason for this.

If two bodies slide at a sliding distance, there is insufficient time for surface undulation to lock each other, thus decreasing the coefficient of friction. Wear rates are based on the coefficient of friction and, because of the increased sliding distance, the friction coefficient decreases. The interactive conditions of PLA and its counter-surface fillers play a significant role in cutting material expulsion. Lower wear rates with a high sliding distance observed and indicated that PLA is very resistant and can effectively prevent composite friction. However, when the sample is present with a continuous axial thrust, neither separation nor pull of fibre and PLA matrix occurs at maximum sliding with higher loads. The glass, granite, and PLA wastes in the W4 sample are perfect for interface adherence and bonding. Moreover, minor fibre fractures increased the load-carrying capabilities.

3.2. Coefficient of Friction ( $\mathrm{CoF})$. The force ratio between the application and the force defines the coefficient of friction. For braking conditions, a steady and higher coefficient of friction is needed. Figures 9 and 10 show corresponding friction coefficients compared with samples of sliding distance 750 and $1500 \mathrm{~m}$ for PLA matrix/fibre/waste nanogranite powder enhancing. The friction coefficient is high and reduced for load increase under lower load conditions.

The possible mechanism used in the sliding test reduces the frictional coefficient and increases the stress of the specimens. The bonding of the fibre matrix is weakened by heat stress at the interface. Due to the repeated pivotal thrust during high loads, the fibres tend to free and scar effectively. The nature of the coefficient friction depends on the interface between a fine polymer film and the type of fibre. When there is heavy loading of mixed waste, it deforms into a thin, cross section-sectional layer of polymers. This film reduces the friction factor due to its thin protective layer.

Presence of oxide decreases oxygen dissemination, increases load transport, and reduces the CoF through waste properties and contact temperature. The friction coefficients for sliding distance 750 metres are higher but decreased at various loads at a more excellent slip range of 1500 metres because of the greater resistance across the pin and sliding matter because the formation or destruction of the film is rapid. The constant surface smoothness at a high sliding 


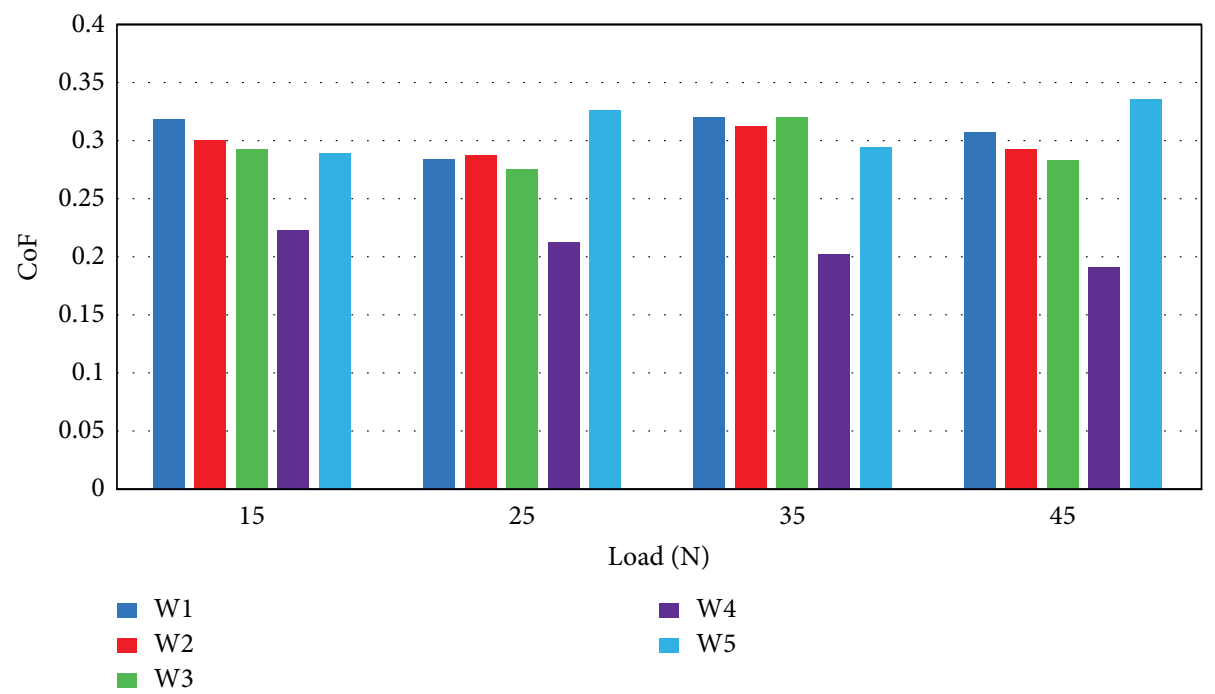

Figure 9: Variation on the coefficient of friction $(\mathrm{CoF})$ of composites for $750 \mathrm{~m}$ sliding distance.

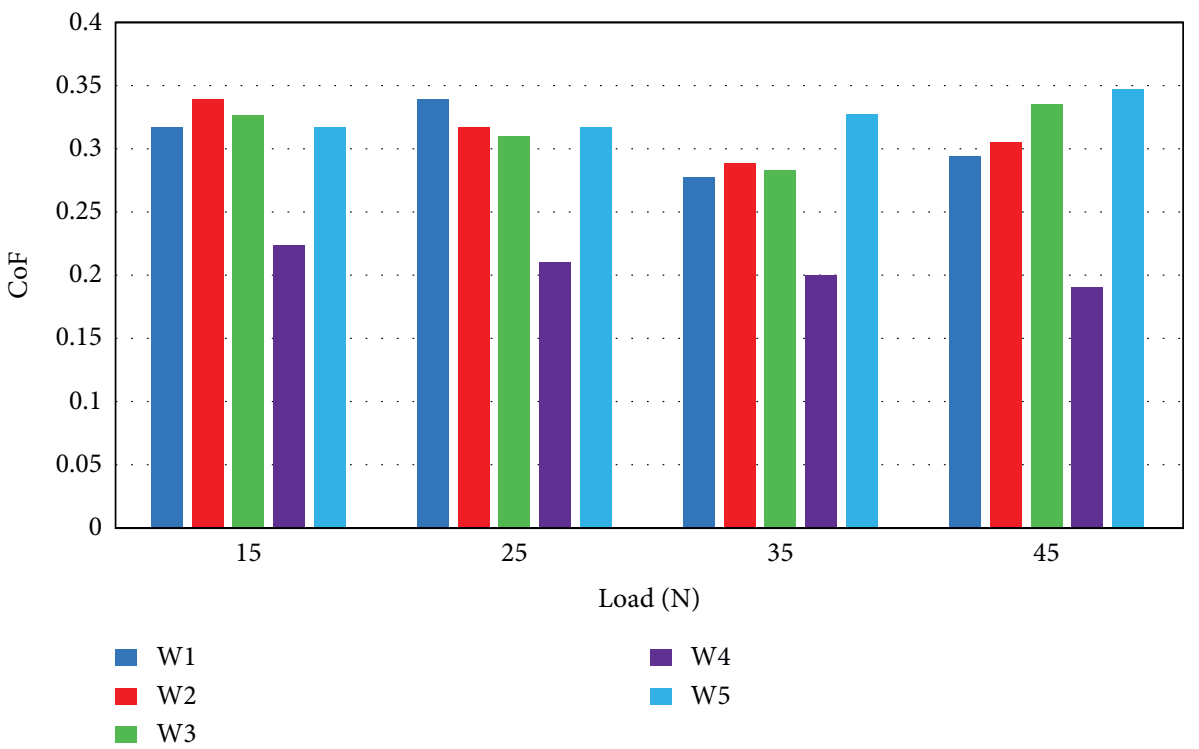

FIgURE 10: Variation on the coefficient of friction $(\mathrm{CoF})$ of composites for $1500 \mathrm{~m}$ sliding distance.

distance also causes it to be determined, and the friction coefficient measures the interactions between the two surface bodies in contact. The presence of oxide reduces oxygen diffusion, increases load transport, and reduces CoF by waste characteristics and contact temperature. The friction coefficient is higher but decreased with various loads at a higher slip range of $1500 \mathrm{~m}$ because of the more excellent resistance between the pin and the sliding material since the transmission film is fastly formed and annihilated. The constant surface smoothness at a considerable slope distance also measures the surface interactions of contact between both bodies by the friction coefficient. The filler material ensures the necessary coefficient friction. The cassava shell expansion estimate of 10 per cent in the samples provides better wear resistance, with little shaking resistance, which reduces material removal in the counterfactual scouring zone. The added examples of PLA show a stable coefficient of friction at the increased load. The composite sample W4 has a lower friction coefficient than W1, W2, W3, and W5. The 12\% filler W4 sample has a low wear ratio and the necessary friction value coefficient. The strength of the connection helps to reduce the material extraction volume. The PLA effectively provides this bonding strength between the fibres and the fillers, leading to the required friction coefficient value.

Therefore, it is apparent that the W4 composite sample has a good friction coefficient obtained from the other composite samples W1, W2, W3, and W5. The example gives you more excellent resistance to wear if PLA, fibre, and filler included in the necessary matrix. The PLA content ensures that the fibre and filler are binding and interfacially connected, making it better for the PLA to add sample W4 cashew. 


\section{Conclusions}

Polylactic acid (PLA) polymer composites have been successfully manufactured using double-screw extrusion and a hot injection moulding technology in the glass fibre/ nanogranite powder. The compound densities gradually increased as the powder of nanogranite and fibre strengthening increased by $3 \%$ to $15 \%$ wt of glass fibre and $4 \%$ to $8 \%$ wt of nanogranite powder. The results showed that PLA polymer composites wear behaviour reinforced with glass fibre/nanogranite powder improved by increasing the reinforcement percentage and increasing the reinforcement to a PLA matrix optimally. The lower wear rate and friction coefficient of four glass fibre/nanogranite reinforced powder polylactic acid polymer composite were $7 \mathrm{wt}$. percent nanogranite powder reinforcement and $12 \mathrm{wt}$. percent glass fibre reinforcement. There is an increase in wear and friction coefficients beyond the $7 \mathrm{wt}$. percent addition of nanogranite powder and $12 \mathrm{wt}$. percent of glass fibres. The wear test results indicate that the wear resistance of the PLA polymer composites specimens of granite powder has increased as reinforcement amounts have raised to an optimal addition of reinforcing materials to the PLA matrix. The most influential factor for specific wear and friction coefficients was found at a load of $45 \mathrm{~N}$ and $1500 \mathrm{~m}$.

\section{Data Availability}

The data used to support the findings of this study are included within the article.

\section{Conflicts of Interest}

The authors declare that there are no conflicts of interest regarding the publication of this article.

\section{Acknowledgments}

The authors thank Sathyabama Institute Science and Technology, Chennai, and Sri Sairam Engineering College, Chennai, for providing facilities support to complete this research work.

\section{References}

[1] G. B. Veeresh Kumar, R. Mageshvar, R. Rejath, S. Karthik, R. Pramod, and C. S. P. Rao, "Characterization of glass fiber bituminous coal tar reinforced Polymer Matrix Composites for high performance applications," Composites Part B: Engineering, vol. 175, Article ID 107156, 2019.

[2] U. K. Annigeri and G. B. Veeresh Kumar, "Method of stir casting of Aluminum metal matrix Composites: a review," Material Today Proceedings, vol. 4, no. 2, pp. 1140-1146, 2017.

[3] A. Atiqah, M. Jawaid, S. M. Sapuan, M. R. Ishak, M. N. M. Ansari, and R. A. Ilyas, "Physical and thermal properties of treated sugar palm/glass fibre reinforced thermoplastic polyurethane hybrid composites," Journal of Materials Research Technology, vol. 8, no. 5, pp. 3726-3732, 2019.

[4] Z. Benzait and L. Trabzon, "A review of recent research on materials used in polymer-matrix composites for body armor application," Journal of Composite Materials, vol. 52, no. 23, pp. 3241-3263, 2018.

[5] J. Naveen, M. Jawaid, E. S. Zainudin, M. T. H. Sultan, and R. Yahaya, "Evaluation of Ballistic Performance of Hybrid Kevlar ${ }^{\circledR} /$ Cocos Nucifera Sheath Reinforced Epoxy Composites," Journal of Textile Institute, vol. 110, 2018.

[6] R. A. Ilyas, S. MohdSapuan, R. Ibrahim et al., "Sugar palm (Arenga pinnata (Wurmb.) Merr) cellulosic fibre hierarchy: a comprehensive approach from macro to nano scale," Journal of Materials Research Technology, vol. 8, no. 3, pp. 2753-2766, 2019.

[7] D. N. Saheb and J. P. Jog, "Natural fiber polymer composites: a review," Adances in Polymer Technology. Journal of Polymer Processing Institute, vol. 18, no. 4, pp. 351-363, 1999.

[8] S. K. Dey and M. Xanthos, "Glass fibers," Funct. Fill. Plast, vol. 21, pp. 141-162, 2010.

[9] F. Tanasa and M. Zanoaga, "Fiber-reinforced polymer composites as structural materials for aeronautics," International Conference Science Paper AF ASES, vol. 10, 2013.

[10] P. D. Mangalgiri, "Composite materials for aerospace applications," Bulletin of Materials Science, vol. 22, no. 3, pp. 657-664, 1999.

[11] R. Pramod and M. E. Shashi Kumar, "Evaluation of mechanical and insulation properties of nomex-T410 and HS glass polymer matrix composites," Materials Today Proceeding, vol. 4, no. 2, pp. 3233-3242, 2017.

[12] S. S. Mathapati and S. S. Mathapati, "Testing and analysis of mechanical properties of E- glass fiber reinforced epoxy polymer composites," International Journal of Research and Innovations in Science and Technology, vol. 2, no. 1, pp. 46-52, 2015.

[13] A. Arun and K. Kumar Singh, "Friction and wear behaviour of glass fibre reinforced polymer composite (GFRP) under dry and oil lubricated environmental conditions," Materials Today Proceeding, vol. 4, no. 8, pp. 7285-7292, 2017.

[14] S. Yadav, Z. Haque, and S. Kumar, "Mechanical and sliding wear behaviour of E-GLASS fiber reinforced with EPOXY composites," International Research Journal of Engineering Technology, vol. 3, no. 5, pp. 563-567, 2016.

[15] C. G. Basavarajappa S, "Wear studies on metal matrix composites Taguchi approach," Journal of Materials Science \& Technology, vol. 21, no. 6, pp. 845-850, 2005.

[16] A. Vaidya and T. Rangaswamy, "A review on E-glass/epoxy composite combined with various filler materials and its mechanical behaviour under different thermal conditions," vol. 7, no. 4, pp. 83-90, 2017.

[17] O. O. Daramola, J. L. Olajide, I. O. Oladele et al., "Mechanical and wear behaviour of polylactic acid matrix composites reinforced with crab-shell synthesized chitosan microparticles," Materials Today Proceedings, vol. 38, pp. 999-1005, 2021.

[18] R. Girimurugan, N. Senniangiri, K. Adithya, and B. Velliyangiri, "Mechanical behaviour of coconut shell powder granule reinforced epoxy resin matrix bio composites," Journal of Advanced Research Dynamical Control System, vol. 10, no. 12, pp. 533-541, 2018.

[19] D. Robson, J. Hague, G. Newman, G. Jeronomidis, and M. Ansell, Survey of Natural Materials for Use in Structural Composites as Reinforcement and Matrices, Biocomposites Centre, Univ. Wales, Bangor, Wales, 1993.

[20] N. Peelman, P. Ragaert, B. Meulenaer et al., "Application of bioplastics for food packaging," Trends in Food Science \& Technology, vol. 32, no. 2, pp. 128-141, 2013. 
[21] P. Gopal, L. R. Dharani, and F. D. Blum, "Fade and wear characteristics of a glass-fiber-reinforced phenolic friction material," Wear, vol. 174, no. 1-2, pp. 119-127, 1994.

[22] S. H. R. Ali, B. S. N. Azzam, T. A. Osman, and A. M. Moustafa, "Experimental investigation and surface characterization of a developed frictional composite material for vehicle brakes," SAE Technical Papers, vol. 2017, pp. 2-7, 2017.

[23] J. Park, H. Hwang, J. Y. Kim, and J. W. Choi, "Applicability of lignin polymers for automobile brake pads as binder and filler materials and their performance characteristics," Environmental Technology, vol. 41, no. 4, pp. 488-497, 2020.

[24] R. Ranganathan, S. Gopal, T. Magudeeswaran, and R. Rangasamy, "Exploration of dry sliding wear behaviour of sisal fiber reinforced cashew nut shell liquid and epoxy polymer matrix composite as an alternative friction material in automobiles," SAE Technical Papers, vol. 28, no. 1, 2019.

[25] S. G. Bajwa, D. S. Bajwa, G. Holt, T. Coffelt, and F. Nakayama, "Properties of thermoplastic composites with cotton and guayule biomass residues as fiber fillers," Industrial Crops and Products, vol. 33, no. 3, pp. 747-755, 2011.

[26] K. R. N. R. K. Kishor Kumar and P. Ramesh Babu, "No title," International Journal of Advanced Mechanical Engineering, vol. 4, no. 1, pp. 371-380, 2014.

[27] K. Surendra and K. Venkateswara Rao, "No title," International Journal of Engineering Trends and Technology, vol. 2, pp. 116-120, 2015.

[28] T. P. Sathishkumar, S. Satheeshkumar, and J. Naveen, "Glass fiber-reinforced polymer composites - a review," Journal of Reinforced Plastics and Composites, vol. 33, no. 13, pp. 1258-1275, 2014. 